\title{
Reflectance microscopy techniques for 3D imaging of the alveolar structure
}

\author{
Carolin Unglert, Eman Namati, Linbo Liu, Hongki Yoo, DongKyun Kang, Brett Bouma, Guillermo Tearney \\ From 2nd Scientific Meeting of the Head and Neck Optical Diagnostics Society \\ San Francisco, CA, USA. 23-24 January 2010
}

Lung disease involving the alveoli and distal bronchioles are poorly understood and most commonly studied indirectly via lung function tests. Available imaging tools for the non-destructive assessment of the alveolar structure include X-ray computed tomography, intra-vital fluorescence microscopy and Optical Coherence Tomography, which are either limited by long acquisition time, inadequate resolution and contrast, or shallow imaging depth.

In this study, we investigated the potential of two highresolution reflectance microscopy imaging techniques, Spectrally Encoded Confocal Microscopy (SECM; $1 \mu \mathrm{m}$ (x) $x 1 \mu \mathrm{m}(\mathrm{y})$ x $5 \mu \mathrm{m}(\mathrm{z})$ resolution) and Full Field Optical Coherence Microscopy (FFOCM; $1 \mu \mathrm{m}$ (x) x $1 \mu \mathrm{m}$ (y) x $1 \mu \mathrm{m}(\mathrm{z})$ resolution), for imaging alveolar microstructural detail. Two mouse lung samples were imaged with both SECM and FFOCM. The specimens were inflation-fixed using a modified Heitzman fixation technique at $20 \mathrm{~cm}$ $\mathrm{H} 2 \mathrm{O}$ pressure. They were cut in $500 \mathrm{~mm}$ thick slices and water immersed for imaging. Images were obtained and analyzed to determine whether or not the resolution and contrast of these techniques are sufficient to visualize the fine structures of the alveolar wall.

Alveolar microstructure could be resolved in three dimensions in images obtained by both technologies. Alveolar septal walls from multiple layers could be clearly identified while sub-cellular structures such as nuclei were also visible in the SECM technique. In conclusion, we have demonstrated that two imaging technologies provide important sub-cellular detail that is required to study alveolar microstructure. Future research to develop these imaging modalities further so that they may be used in vivo is merited.

\footnotetext{
Wellman Centre for Photomedicine, Massachusetts General Hospital, Boston,
} USA
doi:10.1186/1758-3284-2-S1-012
Cite this article as: Unglert et al:. Reflectance microscopy techniques for 3D imaging of the alveolar structure. Head \& Neck Oncology 2010 2(Suppl 1):O12.
Submit your next manuscript to BioMed Central and take full advantage of:

- Convenient online submission

- Thorough peer review

- No space constraints or color figure charges

- Immediate publication on acceptance

- Inclusion in PubMed, CAS, Scopus and Google Scholar

- Research which is freely available for redistribution

Submit your manuscript at www.biomedcentral.com/submit
C Biomed Central 